\title{
Developing a more comprehensive instrument to assess the entrepreneurial mindset of engineering students
}

\section{Dr. Constanza Miranda , Pontificia Universidad Catholica de Chile}

Constanza Miranda holds a PhD in design with a focus in anthropology from North Carolina State University. While being a Fulbright grantee, Constanza worked as a visiting researcher at the Center for Design Research, Mechanical Engineering Department, at Stanford. Today she is an assistant professor at P.Universidad Católica de Chile's Engineering School. There, she directs the DILAB: the engineering design initiative. Apart from developing the educational program in engineering design and innovation (Major IDI), the DILAB partners with forward thinking organizations to assess real life ill-defined issues. Past personal experiences involve work in industry and for consultancies such as Procorp Santiago, Cooper San Francisco and Continuum Milan. On the other hand Constanza is an entrepreneur in medical devices where she is continuously working in the detection of opportunities for innovation and development of new technologies. Her research work is focused mainly in the area of bio design, engineering-design education and design anthropology methods.

\section{Sr. Julián Iñaki Goñi, DILab UC - School of Engineering PUC}

Julián is an educational psychologist from the Pontificia Universidad Católica de Chile, with academic certification in Economy. He is an instructor and research assistant at DILAB UC (School of Engineering UC). He has collaborated in diverse innovation projects. In DILAB UC he researches on topics such as Engineering Education, Public Innovation and Teamwork. He is interested in research, theory and application of interdisciplinary social sciences, with emphasis on the intersection of educational psychology, philosophy and STS

\section{Dr. Bruk T Berhane, Florida International University}

Dr. Bruk T. Berhane received his bachelor's degree in electrical engineering from the University of Maryland in 2003. He then completed a master's degree in engineering management at George Washington University in 2007. In 2016, he earned a Ph.D. in the Minority and Urban Education Unit of the College of Education at the University of Maryland. Bruk worked at the Johns Hopkins University Applied Physics Laboratory, where he focused on nanotechnology, from 2003 to 2005. In 2005 he left JHU/APL for a fellowship with the National Academies where he conducted research on methods of increasing the number of women in engineering. After a brief stint teaching mathematics in Baltimore City following his departure from the National Academies, he began working for the Center for Minorities in Science and Engineering (CMSE) in the Clark School of Engineering at the University of Maryland. In 2011, he began working directly under the Office of the Dean in the Clark School, coordinating outreach and recruitment programs for the college. In 2016, he assumed the role of director of the Office of Undergraduate Recruitment and Scholarship Programs. His duties entailed working with prospective freshmen and transfer engineering students. In 2019, he transitioned to the role of Assistant Professor in the School of Universal Computing, Construction and Engineering Education at Florida International University. His research interests transfer students who first enroll in community colleges, as well as developing broader and more nuanced engineering performance indicators.

\section{Ms. Trinidad Sotomayor, Pontificia Universidad Católica de Chile}

Trinidad is an Engineering Design Master Student at Pontificia Universidad Católica de Chile (UC). She owns a bachelor degree in mechanical engineering with a major in Design and Innovation. At DILAB (UC), the engineering design initiative, Trinidad has been working as a researcher in topics regarding engineering education such as entrepreneurship, epistemologies and minorities, among others. 


\title{
Work in Progress: Developing a more comprehensive instrument to assess the entrepreneurial mindset of engineering students
}

\begin{abstract}
This is a Work in Progress: Goals of becoming more entrepreneurial have placed considerable pressure on institutions of higher education to generate educational programs that are consistent with the entrepreneurial mindset. Surpassing business programs, engineering education has had an exponential growth in entrepreneurship instruction in curricula and publications related to the topic. However, there are still many conceptual and methodological challenges described in recent literature left unresolved by current assessment methods. As an international and interdisciplinary research team, we seek to develop a new survey instrument to assess the entrepreneurial mindset in engineering students. In the next two years, a preliminary quantitative version of the instrument will be applied to an incrementally larger body of Chilean and United States students in order to evaluate its utility across a much larger sample size. Through this research effort and a critical review of the literature, we aim to produce a more comprehensive and situated method for defining and articulating the entrepreneurial mindset for stakeholders in engineering education. Long-term implications for this project include alignment of the entrepreneurial mindset with objectives articulated by the Accreditation Board for Engineering and Technology (ABET).
\end{abstract}

\section{Introduction}

The entrepreneur is considered in today's society as a social ideal and almost as a mythical hero (Pilotta, 2016). This conception is possibly related to the overall impression that entrepreneurship is a powerful vehicle for economic development all around the world (Greene $\&$ Saridakis, 2008). This perception of entrepreneurship has led more institutions of higher education to generate educational programs that are consistent with the entrepreneurial mindset (Fretschner \& Weber, 2013; Kuratko, 2005). These programs are usually broadly categorized as "entrepreneurship education" and are based on the premise that entrepreneurship can be taught and learned (Fretschner \& Weber, 2013). Grounded in this premise and since its growth since 1947, there are now more than 3,000 programs on entrepreneurship education around the world (Morris \& Liguori, 2016). While originally these programs were incorporated into business schools, they have rapidly expanded into other disciplinary domains. Engineering, perhaps because of the global interest in technological entrepreneurship, has become one of the main champions of entrepreneurship education outside business schools. 
More than half of engineering programs accredited by the American Board of Engineering Technology (ABET) offered entrepreneurship education options as of 2008 (Shartrand, Weilerstein, Besterfield-Sacre, \& Golding, 2010). However, despite the exponential growth of engineering entrepreneurship education, there are still many challenges left in order to institutionalize it an academic and theoretically grounded subfield of study. For instance, one of the most prominent frameworks developed for engineering entrepreneurship education is the one promoted by the Kern Entrepreneurship Education Network (KEEN) from the Kern Family Foundation (Kriewall \& Mekemson, 2010). This framework is beneficial to schools that need a starting point with clear implementation guidelines. Nonetheless, it does not consider new theories or questions related to entrepreneurial learning from the contemporary theoretical debates and research grounding (Huang-Saad, Bodnar, \& Carberry, 2020). This presents an opportunity for scholars to both develop more conceptualizations and assessments of engineering entrepreneurship grounded in research, and also to distinguish it from other frameworks in entrepreneurship-based research.

\section{Study Design}

This study is the first phase of a multi-year approach that utilizes both qualitative and quantitative methods. This approach will operationalize the development of a comprehensive instrument that seeks to fill a lacunae in literature as it relates to conceptualizing and assessing the entrepreneurial mindset. We began in early 2019 by developing an initial set of dimensions of the entrepreneurial mindset by conducting a thorough review of extant literature. The dimensions that we identified were grouped into the following categories: (1) Behaviors; (2) Examples; and (3) Educational Practices associated with the entrepreneurial mindset in engineering. Then, in the first few months of 2019, our team jointly developed research protocols that employed these dimensions, and then conducted qualitative workshops, which we define as a structured conversation guided by elicitation activities. Workshops were conducted with mostly undergraduate engineering students, one graduate student, as well as with faculty; student workshops were held separately from the faculty workshops. The first set of workshops were conducted at the Pontificia Universidad Católica de Chile (Pontifical Catholic University of Chile, or PUC) in May and June of 2019, and the second set of workshops were conducted at the University of Maryland (UMD) in July of 2019. At both universities, we recruited engineering professors, engineering education scholars, and current engineering students. At PUC, we employed snowball and purposive sampling to identify faculty who teach engineering students, and both undergraduate and graduate students who teach and learn about support entrepreneurship, respectively. At UMD, the third author, who was employed at the time on that campus as an assistant research professor, utilized his professional on-campus network to identify faculty who teach in or lead entrepreneurship programs, faculty who are involved in engineering education research, and students who were mentoring participants in an on-campus 
high school summer engineering camp. This sequential explanatory mixed method research design is being conducted in order to solve the following research questions:

RQ1: What are the fundamental definitions components of the entrepreneurial mindset in engineering education?

RQ2: How can this alternative conceptualization, grounded in educational theory, can be assessed through a cross-national quantitative survey fulfilling standards in both validity and reliability?

\section{Theoretical Framework}

When designing and evaluating entrepreneurship education programs, there is usually a primary focus on identifying entrepreneurial intentionality (Pittaway \& Cope, 2007), that is, a declared interest in creating a business. This poses a problem insofar as there is a richness in the entrepreneurial mindset and cognitive process (Haynie, Shepherd, Mosakowsky \& Earley, 2010) that extends beyond the process of creating companies. Moreover, if the entrepreneurial mindset provides deeply adaptive cognitive strategies, there is an argument to be made about the value of having an entrepreneurial mindset in any organizational context. Most of the 'cognitive' approaches to entrepreneurship tend to conclude that this mindset is based in the ability "to sense and adapt to uncertainty" (Haynie, Shepherd, Mosakowsky \& Earley, 2010 p.218). According to this definition, every student would benefit by cultivating the capacity to be dynamic, flexible and self-regulating (Haynie, Shepherd, Mosakowsky \& Earley, 2010) in their educational and work experience, whether or not they create a business.

On the other hand, the rapid growth in teaching entrepreneurship has not been met with a comprehensive understanding of the process that undergirds entrepreneurship education (Morris \& Ligouri, 2016). Morris and Ligouri (2016) argue that more research is needed to address several key research questions: How is entrepreneurship taught? What content should be provided to students? How should we evaluate results? In sum, there is a double gap to address in entrepreneurship education: 1) What is the value of entrepreneurship beyond creating businesses? 2) How should it be taught and measured? Both questions are deeply intertwined and will require the integration of findings both in entrepreneurship literature and also in contemporary learning theory.

Mäkimurto-Koivumaa and Belt (2016) propose a competency model for entrepreneurship education in non-business programs. In their analysis, engineering competencies that go beyond the traditional basic sciences are consistent with recent conceptualizations of the entrepreneurial mindset. For engineers adopting the entrepreneurial mindset, a balance must be achieved between increased technical knowledge and broad general competencies (de Graaff \& Ravenstein, 2001). Nonetheless, entrepreneurship as a particular mindset seems to be mostly 
connected to cognitive strategies (Haynie, Shepherd, Mosakowsky \& Earley, 2010) and general competencies (Mäkimurto-Koivumaa \& Belt, 2016), more so than discipline-specific content.

\section{Methodology}

We propose that key competencies can be identified in entrepreneurship research and that they can be explored through the knowledge of learning theory and engineering education. As a result, educational outcomes can be defined that can benefit all students and can also be assessed. This will require a critical review of literature in order to select findings developed through strong methodologies and robust theoretical frameworks. Graduate research assistants, including both doctoral and master's degree candidates, will be included as key personnel in the review of the literature. As an end product, we propose the construction of an entrepreneurship survey for the specific context of engineering education. This survey will be developed through substantive qualitative and quantitative methodological foundations and cross-cultural validation. In addition, qualitative methods will be fundamental to building and grounding our work; they include interviews and workshops with students to identify salient themes. These themes will then be measured as part of quantifiable surveys. Most importantly, these themes reflect a more robust and inclusive concept of entrepreneurship that extends beyond business-related entrepreneurial intent. This is particularly relevant in the spirit of educational inclusion. Indeed, not all students may start a new business, but we assert that all students ought to have the opportunity to explore the significance of developing an entrepreneurial mindset. Simultaneously, engineering faculty will potentially benefit from being able to integrate components of the entrepreneurial mindset in their courses.

To tackle our research questions, we implemented a qualitative research design in order to identify constructs and items. First, we started by conducting a critical review of the literature to identify key components of the entrepreneurial mindset. As Figure 1 shows, this review was in the disciplinary areas of a) education or learning theory b) engineering education and c) business management.

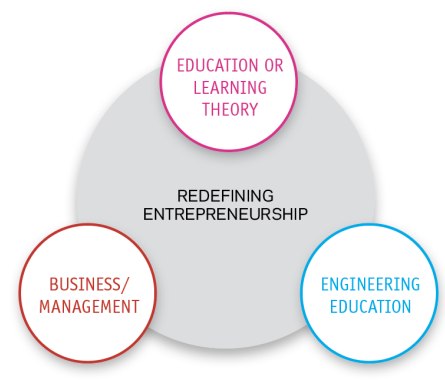

Fig1: Disciplinary areas for literature review 
The first stage yielded the identification of key components that define these three disciplinary areas. These involved elements such as: risk tolerance, empathy, pro-activity, co-regulation, etc. We could find homologues in entrepreneurship and learning theory. Nonetheless, there were gaps as it related specifically to engineering education. Therefore, as Figure 2 shows, we needed to triangulate this information with sources derived from praxis like the perceptions of students, instructors, and professors involved in engineering courses.

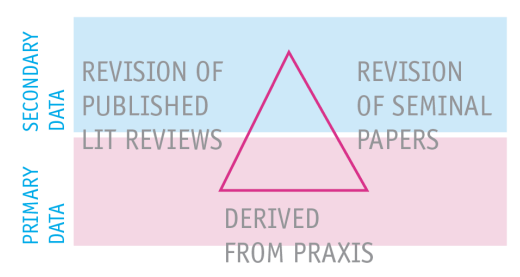

Fig2: Triangulation of information by sources

The second stage was exclusively qualitative in nature. It consisted of five hour-long workshops and two semi-structured interviews carried out in Chile and the United States between May and July of 2019. The participants involved a total of 19 students and 9 professors/instructors in engineering, 12 of whom identified aswomen and 17 of whom identified as men. The undergraduate and graduate students that participated ranged from engineering disciplines such as: industrial engineering, mechanical engineering, civil engineering, environmental engineering, biomedical engineering, computer sciences, electrical engineering, transportation engineering, etc. Ages of the repsondents ranged from 18 to 25 years old. In the cases of the faculty, they represented project based courses, Science, Technology, and Society, or courses that dealt with developing entrepreneurial ideas; in addition to their teaching responsibilities, three of the faculty have research interests in engineering education. The workshops and interviews sought to identify behaviors, classroom or real-world examples, and educational practices related to entrepreneurship in engineering. The workshops were recorded, transcribed and the ones in Spanish were translated into English using a third party provider.

In the third stage, the raw qualitative data was analyzed using a two-phase coding process. In the first phase, each data production event was coded as behaviors/practices and classified into three categories: conducts, examples, or educational practices. In the second phase, identified behaviors/practices were regrouped into major themes. The next step of our research project is to translate the qualitative results into survey items

\section{Conclusions}

The methodology used in this research project demonstrates the possibility of a critical integration of theory, as well as qualitative inquiry. It is our assertion that good assessment methods arise from both these sources. 
Our work will derive its theoretical underpinnings from extant literature across multiple disciplines, and has the potential to directly impact students and faculty in all engineering subject areas. Furthermore, our multi-national team and research approach suggests opportunities to interrogate the implications of our work in different cultural contexts. Finally, in response to the need to develop more globally engaged engineers who are able to creatively solve problems (Jesiek, Zhu, Woo, Thompson, \& Mazzurco, 2014), our findings can inform engineering education in various ways.

\section{References}

de Graaff, E., and W. Ravesteijn. (2001). "Training Complete Engineers: Global Enterprise and Engineering Education.” European Journal of Engineering Education 26 (4): 419-427.

Fretschner, Michael, and Susanne Weber. (2013). "Measuring and Understanding the Effects of Entrepreneurial Awareness Education." Journal of Small Business Management 51 (3): $410-28$.

Greene, Francis J., and George Saridakis. (2008). "The Role of Higher Education Skills and Support in Graduate Self-Employment." Studies in Higher Education 33 (6): 653-72.

Haynie, J. M., Shepherd, D., Mosakowski, E., \& Earley, P. C. (2010). A situated metacognitive model of the entrepreneurial mindset. Journal of Business Venturing, 25(2), 217-229.

Huang-Saad, A., Bodnar, C., \& Carberry, A. (2020). Examining Current Practice in Engineering Entrepreneurship Education. Entrepreneurship Education and Pedagogy, 3(1), 4-13. https://doi.org/10.1177/2515127419890828

Jesiek, B. K., Zhu, Q., Woo, S. E., Thompson, J., \& Mazzurco, A. (2014). Global engineering competency in context: Situations and behaviors. Online Journal for Global Engineering Education, 8(1), 1.

Kriewall, T. J., \& Mekemson, K. (2010). Instilling the entrepreneurial mindset into engineering undergraduates. The Journal of Engineering Entrepreneurship, 1(1), 5-19.

Kuratko, D. F. (2005). The emergence of entrepreneurship education: Development, trends, and challenges. Entrepreneurship Theory and Practice, 29(5): 577-598. 
Mäkimurto-Koivumaa, S., \& Belt, P. (2016). About, for, in or through entrepreneurship in engineering education. European Journal of Engineering Education, 41(5), 512-529.

Morris, M. H., \& Liguori, E. W. (2016). Preface: Teaching reason and the unreasonable. In M. H. Morris \& E. W. Liguori (Eds.), Annals of entrepreneurship education and pedagogy (Vol. 2). Northampton, MA: Edward Elgar Publishing.

Pilotta, J. J. (2016). The entrepreneur as hero? In V. Berdayes \& J. W. Murphy (Eds.), Neoliberalism, economic radicalism, and the normalization of violence (pp. 37- 52). New York, NY: Springer.

Pittaway, Luke, and Jason Cope. (2007). Entrepreneurship Education a Systematic Review of the Evidence. International Small Business Journal 25(5): 479-510.

Shartrand, A., Weilerstein, P., Besterfield-Sacre, M., \& Golding, K. (2010). Technology entrepreneurship programs in U.S. engineering schools: Course and program characteristics at the undergraduate level. Proceedings of the American Society for Engineering Education, Louisville, KY 